\title{
А. А. Иваненко
}

\section{И. Г. ФИХТЕ ОБ УНИВЕРСИТЕТСКОМ ОБРАЗОВАНИИ}

Статья посвящена анализу роли университетского образования в развитии науки и преобразовании общества, осуществленному И. Г. Фихте в практически неизвестной российскому читателю работе «Дедуцированный план создаваемого в Берлине высшего учебного заведения, надлежащим образом связанного с Академией наук». Для реконструкции позиции Фихте в статье решаются следующие задачи: во-первых, устанавливается понятие философии как наукоучения; во-вторых, исследуется его влияние на современное Фихте понимание научности; в-третьих, анализируются предложенные мыслителем изменения в форме и содержании университетского образования. Опираясь на методы сравнительного и текстологического анализа, автор приходит к следующим выводам. Философия, по Фихте, должна установить принципиальный способ деятельности духовной субстанции (интеллигенции) и вывести из него все ее основные способы деятельности. Применительно к науке это означает выявление всех основных ее методов и предметных сфер. Для подъема науки на более высокую ступень осознанности немецкий философ предлагает значительно увеличить объем преподавания философии в университете. Кроме того, он ратует за изменение доминирующего в университетском образовании способа преподнесения обучающимся готовых результатов на способ раскрытия проблем и методов науки в непрерывном диалоге с преподавателем, требующем самостоятельной интеллектуальной активности студентов. По мысли Фихте, реформа университетского образования позволит формировать ученых, обладающих нравственным умонастроением и способных оказать значительное влияние на жизнь общества. Предлагаемые великим идеалистом XIX в. меры по усилению положительного влияния науки и образования на изменения общественной жизни заслуживают пристального внимания и сегодня, поскольку позволяют перевести прагматический подход к образованию и науке в более широкий мировоззренческий контекст. Библиогр. 6 назв.

Ключевые слова: И.Г. Фихте, наукоучение, наука, образование, университет, общество.

\section{A. A. Ivanenko}

\section{J. G. FICHTE ABOUT UNIVERSITY EDUCATION}

The article analyzes the role of university education in the development of science and the transformation of society. The textual basis of the study relies on central points of J. G. Fichte's project of creation of the University which is represented in his text, as yet untranslated into Russian, "Deduzierter Plan einer zu Berlin zu errichtenden höhern Lehranstalt, die in gehöriger Verbindung mit einer Akademie der Wissenschaften stehe". For the reconstruction of Fichte's position, the following problems are solved in the article: 1) The concept of philosophy as a Science of Knowledge is established;2) Its influence on the understanding of the property of scientific investigation in the 19th century; 3) The changes in the form and content of university education. According to the German philosopher further social development is results from the release of science to a new level of scholarship. The latter is impossible without radical transformation of the scientific and educational life of universities. The essence of Fichte's proposals relates to changes in the teaching of philosophy. Philosophy is addressed to students of all disciplines and should be taught in the university to a greater extent. Therefore, it is necessary to change the method of teaching philosophy. Instead of presenting historical amounts of information it is necessary to demonstrate the genesis of scientific problems and methods. Thus science, reaching clarity about its nature and tasks can become the decisive factor of social progress. The author stresses

Иваненко Антон Александрович - кандидат философских наук, доцент, Санкт-Петербургский государственный университет, Российская Федерация, 199034, Санкт-Петербург, Университетская наб., 7-9; antonivanenko@mail.ru

Ivanenko Anton A. - PhD, Associate Professor, St. Petersburg State University, 7-9, Universitetskaya nab., St. Petersburg, 199034, Russian Federation; antonivanenko@mail.ru

(c) Санкт-Петербургский государственный университет, 2017 
that measures proposed by the great idealist of the 19th century have a significant degree of relevance for the present stage of development of science and university education. Refs 6 .

Keywords: J.G. Fichte, The Science of Knowledge, science, education, University, society.

В последние три десятилетия наша страна переживает период смены ориентиров. Частный интерес, отношение к которому в предыдущий период нашей истории было резко отрицательным, оказался не просто реабилитирован, но объявлен чуть ли не главной ценностью в жизни человека и общества. Под флагом этой идеологемы прошел процесс социального расслоения, который, хотя и переживался обществом очень болезненно и нередко встречал крайне негативные оценки, все же к настоящему моменту уже стал свершившимся фактом. Но если первые два десятилетия этого процесса образование с его идеологической стороны оставалось относительно мало затронутым сменой ориентиров (чего не скажешь о материальной стороне его существования), то в последние десять лет стремление его реформировать исходя из обозначенного выше посыла заявляло о себе все активнее. С этой точки зрения образование имеет чисто прагматическое назначение - отдельному человеку оно должно давать средства для достижения его частных целей, а раз успех достигается в обществе, то образование именуют при таком взгляде средством социализации. Поскольку же полагают, что состоятельность государства определяется мощью национальной экономики, то задачу государства видят в управлении, наиболее эффективном в экономическом отношении. Этот взгляд естественным образом распространился и на политику в области образования. Образование и со стороны государственных интересов рассматривается здесь исключительно в прагматическом ключе - как средство экономического преуспеяния страны. Необходимость консолидации общества не исключительно на экономической основе, конечно, также не полностью терялась из вида, но для этого собственно в системе образования полагали достаточным оставить некоторое крайне ограниченное количество школьных предметов, связанных с поддержанием культурной идентичности (в старших классах - нечто о России в мире). По видимости, в этом деле более значительная роль отводилась общественно-политическим мерам наподобие поддержки спорта больших достижений, традиционных конфессиональных организаций и части художественной интеллигенции. Духу данного взгляда на образование отвечают и именование образования «сферой образовательных услуг», и последовательное расширение области платного в образовании.

Позиция, изложенная выше, достаточно последовательна. Но два обстоятельства заставляют скептически отнестись к ее продуктивности: во-первых, то, что может быть построено на ее основе в виде образования, не дает никаких гарантий того, что те, кто должны будут реализовывать государственные цели и задачи, получив такое образование, будут в состоянии верно их усмотреть. И во-вторых, даже при условии верного установления таких целей, нет никакой уверенности, что они будут в состоянии успешно их реализовывать. И то и другое требует образования не только рассудка, но и нравственного умонастроения. Но здесь упомянутая идеологема бессильна, она создает почву только для частных - приватных и сословных - целей. Еще до полной реализации планов реформирования образования в таком духе можно было с уверенностью предсказать их небезопасность для целого национальной жизни, как и то, что вне зависимости от того, как конкретно 
будут развиваться события, запрос на иной, более адекватный потребностям этой жизни проект образования рано или поздно появится. С нашей точки зрения, такой более адекватный, в том числе и самой природе образования, взгляд на него развивает Иоганн Готтлиб Фихте. В данной статье мы сконцентрируем внимание на роли университета в изменениях системы образования, предлагаемых Фихте, оставив в стороне большую часть вопросов о народной школе и национальном воспитании, изложенных в его труде «Речи к немецкой нации», поскольку он уже переведен на русский язык и доступен российскому читателю [1]. Роли же университета в этих изменениях посвящена не переведенная до сих пор на русский язык работа немецкого классика «Дедуцированный план создаваемого в Берлине высшего учебного заведения, надлежащим образом связанного с Академией наук» (1807).

В «Дедуцированном плане» Фихте пишет, что современная эпоха отличается «почти всеобщей буржуазностью» [2, S.111]. Буржуазность, разумеется, не есть что-то совершенно дурное, но буржуазия характеризуется Фихте как «занятая ремеслом и бессмысленно наслаждающаяся» [2, S.111]. Истинный интерес ее представителя заключается в «семейной жизни» и «содействии промыслу родителей» [2, S. 110], т. е. сконцентрирован на частных интересах, в то время как необходимо, чтобы «в государстве, и в особенности у его высших служителей, прочно укоренился такой образ мысли, при котором обществу служат не затем, чтобы иметь возможность жить, но хотят жить лишь затем, чтобы мочь служить обществу» [2, S. 112]. И далее Фихте добавляет: «...но такой образ мысли может пустить корни только в духе, облагороженном жизнью в науке» [2, S. 112]. Если мы обратимся к нашим современным обстоятельствам, то увидим картину, на первый взгляд, противоречащую этому положению, а именно, что научное образование, по всей видимости, не сыграло той благотворной роли, которая утверждается за ним Фихте. И с этим недоумением мы сразу оказываемся в центральном пункте предлагаемой великим философом перемены.

Отводя науке фундаментальную в формировании личности и общества роль, Фихте имеет в виду не любое фактическое состояние науки. Центральную часть своей философии Фихте обозначил как наукоучение, т.е. такое учение о науке, которое в корне преобразовывает ее понимание. Обычное представление о науке состоит в том, что она есть множество «научных» дисциплин, каждая из которых обладает собственным особенным предметом и собственными «научными» методами. Причем в этом случае не ставятся вопросы о том, каким образом вообще возможно познание предметов наук, которые представляются отличными от познающего их субъективного мышления, как и на каком основании формируются представления об этих предметах, в чем заключается «научность» научных методов. При таком положении дел наука остается во многом бессознательной и в строгом смысле слова ненаучной. Упомянутое преобразование понимания науки Фихте как раз и состояло в том, что он предпринял попытку ответить на эти вопросы удовлетворительным образом.

Любая форма представления или знания есть, по Фихте, в конечном итоге форма самораскрытия и самосознания духовной субстанции, именуемой им интеллигенцией. Наука в целом есть знание совокупных законов деятельности интеллигенции, а каждая частная наука - знание особенных законов этой деятельности. Философия же, или наукоучение, выявив субстанцию знания, а значит, и науки, обо- 
сновывает все формы знания, как в отношении его предметов, так и в отношении его методов, тем, что последовательно выводит их как формы самодеятельности субстанции. При условии успешного осуществления такого выведения наука оказывается способной подняться на совсем иной уровень научности, т. е. сознательности, целенаправленности и методичности своих действий. Ученый же, знающий о том, что его деятельность представляет собой одну из форм самосознания духовной субстанции, безусловно, есть нравственное существо. Науку именно в таком состоянии и имеет в виду Фихте в своих сочинениях [3; 4]. В рассматриваемом произведении великий идеалист, не углубляясь в теоретические вопросы обоснования науки [5; 6], обращает свое внимание на форму научного образования.

Университеты, по Фихте, возникли в свое время в ответ на потребность в «возведении, сохранении и расширении здания науки» [2, S.97] в условиях редкости и труднодоступности другого средства для этого - книги. В связи с этим и способ преподавания в университетах представлял собой эрзац книги - учащимся преподносился тот же самый материал, причем аналогичным способом, наука излагалась как ряд положений догматическим образом в монологе лектора. При такой форме обучения остается делом случая, проникает ли обучающийся в сам дух науки или просто запоминает услышанное. Если имеет место последнее, то при знакомстве с результатами науки собственно научного образования души учащегося не происходит и вполне вероятно обратное - возникновение отвращения или презрения к науке. Доступность книги ко времени Фихте поставила на повестку дня вопрос о преобразовании характера обучения (от себя добавим, что в наши дни изза появления сети Интернет и, как следствие, общедоступности информации этот вопрос стал еще более острым). В связи с этим изменения требовали и требуют все отрасли образования, но изменение общей средней («народной», по терминологии Фихте) школы, так же как и элитарного среднего образования («низшей научной школы»), невозможно без изменения университетского образования, являющегося вершиной «искусства образования человека» [2, S.116]. Но так как университетское образование есть научное образование, то такое изменение невозможно без изменения состояния науки. «Особенная наука, - пишет Фихте, - <..> во всех своих отдельных отраслях есть особенное действие и произведение посредством духовной способности» [2, S. 121]. «Дух каждой особенной науки - ограниченный и ограничивающий дух, который хотя и живет в себе самом, действует и приносит драгоценные плоды, не в состоянии понять ни себя, ни другой дух вне себя» [2, S.121]. Лишь философия в состоянии научно постичь всю совокупную духовную деятельность. Искусство каждой особенной науки представляет собой определенное применение духовной способности, и подготовка к ней требует основательного упражнения в искусстве философии. Последняя не должна ограничиваться в университете ролью одного из особенных факультетов, но должна быть для него в целом источником формирования его научного характера и ферментом дальнейшего научного развития. При этом условии университетская наука избавится от партикулярности и слепоты в отношении целого науки, его задач и направленности. Это можно показать на примере юриспруденции. По Фихте, «научный материал юриспруденции есть раздел истории» [2, S. 133], содержащий историю «возникновения и развития понятия права у людей» [2, S. 133]. Ясно, что без понятийной подоплеки этот материал дает лишь картину исторической изменчивости права, что само по 
себе вовсе не содействует научной трактовке его природы, законов возникновения и изменения, вместо этого возбуждая релятивистские умонастроения. Надежно избежать этого можно лишь с помощью философии - установив понятие права, его необходимость и место в духовной деятельности, что как раз и даст возможность в кажущемся хаосе событий усмотреть упомянутые законы.

Фихте называет рассудок «свободной деятельностью постижения» [2, S. 101], а должный возникнуть университет - «школой научного применения рассудка» [2, S. 101]. Если критикуемая им догматическая форма научного образования прежде отвечала догматической же, во многом слепой в отношении себя самой форме существования науки и до некоторой степени удовлетворяла научные потребности своего времени, то новое, осознанное существование науки требует и сознательного овладения научностью. А это не может быть достигнуто путем преподнесения готовых результатов или методов науки. Каждый из них, для того чтобы стать собственным сознательным достоянием ученого, должен быть открыт им в учении как закон или результат его собственной духовной деятельности. И потому обучение должно быть «непрекращающейся беседой» в духе «школы Сократа» [2, S. 104], в ходе которой преподаватель не дает готовых ответов, а предоставляет учащемуся материал для самостоятельного осмысления, тем самым возбуждая его собственную активность в этом направлении. По качеству осмысления студентом открывшихся ему проблем обучащий может понять, на какой ступени освоения искусства философствования тот находится в настоящий момент, и в соответствии с этим дать ему дальнейший материал, открывая учащемуся новый круг вопросов. Для этого преподаватель, разумеется, сам должен иметь четкое представление о ходе развития духовной активности и при предоставлении материала следовать соответствующему этому развитию плану. В ходе такой «беседы» «каждое слово учителя должно быть ответом на вопрос ученика, вызванный непосредственно предшествующим, и постановкой перед ним нового вопроса» [2, S. 104]. В таком процессе преподаватель имеет дело не с неизвестным субъектом, а со все более и более открывающейся ему личностью, и всегда оказывается в состоянии воспринять ее актуальную мыслительную потребность и в гораздо большей степени, чем в первом случае, способен добиваться достаточного понимания изучаемого.

Для успеха образования, с точки зрения Фихте, также важно создание в среде учащихся соответствующего нравственного климата. Мелочная забота о повседневных жизненных потребностях вредит учебе, и потому студенты должны быть в достаточной мере обеспечены всеми необходимыми средствами существования, а при вступлении на путь научной карьеры - приличествующим содержанием. Студенты при этом должны вести общее хозяйство, обеспечиваемое всем необходимым со стороны университета. Это нужно для того, чтобы учащиеся ради науки могли составить единую общину, чтобы и в общении между собой пребывать в движении научной жизни, когда каждый представляет науку с той стороны, с которой он ее усвоил, и взаимно продвигать друг друга в формировании науки в них самих. Для этого Фихте полагает также необходимым отделить студентов от «буржуазной жизни» и учащихся ради ремесла.

Понятно, что, согласно этому плану, к преподаванию может приступить лишь тот, кто в достаточной мере освоил искусство философии и особенное искусство своей науки. Таким образом, по мысли Фихте, может быть обеспечено научное 
в точном смысле слова, т.е. сознательное владение наукой. Учебные курсы в университете при этом должны быть двух типов. Основы каждой особенной науки должны быть изложены в энциклопедии соответствующей науки, над усовершенствованием которой преподаватели данной дисциплины должны постоянно продолжать работать. Первым курсом при преподавании этой науки должен быть курс по ее основам, т. е. опирающийся на такую энциклопедию. Но за этим исключением преподаватели не должны читать никаких курсов по материалу, уже изложенному в научных сочинениях. Все необходимое для освоения этой науки и доступное в печатном виде должно быть освоено студентом в обязательном порядке самостоятельно. Остальные учебные курсы должны представлять собой курсы по впервые разрабатываемым самими преподавателями проблемам данной науки, еще не нашедшим отражения в специальной литературе.

Два века, истекших со времени создания Фихте проекта университета, не прошли для науки и научного образования бесследно. Количество высших учебных заведений и доля учащихся в них по отношению ко всему населению значительно выросли в сравнении с началом XIX столетия. Увеличилось, по видимости, и влияние науки на жизнь общества и государства. Но перемены эти были несколько иного свойства, чем те, что предлагались Фихте. Распространение научного знания и образования произошло не в силу прояснения их основ, целей и методов, но в силу очевидной практической полезности их результатов. Разного рода техника, от машинной до техники управления обществом, ставшая первейшим плодом науки, давала материальное благополучие и обеспечивала мощь государствам, что и вызвало к жизни политику распространения научного образования. Однако по этой же причине распространение науки и научного образования носило преимущественно экстенсивный характер. Принято считать, что именно в последние два столетия наука добилась наибольших успехов. Но в это же время постоянно усиливались и негативные последствия применения достижений науки. Экологический, демографический, экономические и политические кризисы - антропогенного происхождения и не были бы возможны без науки в том виде, как она есть налицо в эти два столетия. Хотя в виде своих частных отраслей и теорий наука за это время шагнула далеко вперед, в самой своей идейной и методологической основе она осталась на уровне XVII и XVIII вв. Усиление же мощности ее воздействия на существование человека и человечества в этот период лишь делает потребность в перемене в указанном отношении все более настоятельной.

Наука, таким образом, до сих пор не вышла на более высокий уровень научности, и меры, предлагаемые Фихте для изменения положения дел в этом отношении, по-прежнему представляют интерес и проблему для организации научного образования. Во-первых, мысль Фихте об отделении науки от «буржуазной жизни» продуктивна и в современных условиях. В них, на наш взгляд, она может быть реализована тем образом, что так называемая чистая наука должна быть поставлена в принципиально другие условия существования, чем наука, ориентированная на разного рода практические достижения. Если деятельность технических, экономических и педагогических вузов может и должна быть оценена по ее практической эффективности (что, впрочем, также не столь просто, как может показаться), то чистая наука не должна быть институционально связана с непосредственным практическим использованием ее результатов и финансово зависеть от него. Универси- 
тет в классическом виде, о котором и идет речь у Фихте, и Академия наук вовсе не утратили своего значения оттого, что развитие общества и науки привело к возникновению большого количества технически ориентированных высших учебных заведений. В случае их смешивания с последними наука обречена оставаться всего лишь средством реализации не ею определяемых целей, и ее влияние на существование человечества будет не только положительным, но и отрицательным.

Но указанная мера, во-вторых, не сможет дать желаемого эффекта без еще одной меры также являющейся модификацией посыла Фихте в нынешних условиях. А именно: для того чтобы наука оказалась в состоянии стать в значительной степени самоуправляющимся сообществом ученых, требуется, как было сказано выше, достичь большей сознательности ученых в отношении науки. Для этого необходимо увеличить роль философии в высшем образовании. И в этом плане мы имеем, по видимости, некоторый прогресс по сравнению с ситуацией начала XIX в. Философия ныне является в вузах обязательным предметом, а также в виде «истории и философии науки» преподается в аспирантуре готовящимся к научной деятельности. Но этот прогресс очень относителен, так как философия преподается студентам в основном на первом году обучения. То, что философия встречает студента в самом начале его научного образования, представляется правильным, но при этом курс философии продолжается только один, от силы два семестра. В этой ситуации, во-первых, студенты имеют дело с философией, будучи наименее к ней подготовленными за все время обучения, что делает их знакомство с ней довольно неэффективным, и во-вторых, столь небольшой срок, отведенный на знакомство с философией, практически исключает возможность детального усвоения ее развития и результатов. Не поступающие в аспирантуру никогда и нигде не компенсируют этот недостаток. Но даже и аспирантам, т.е. людям, подготавливающимся к научной деятельности, он не может быть полностью компенсирован курсом по истории и философии науки, поскольку этот курс не предусматривает углубления в собственно философию. История науки в смысле освещения фактического хода ее развития вообще не является высокотеоретичным предметом и должна быть, как представляется, преподаваема в качестве общего курса для студентов. История же науки в смысле развития понятия науки неотделима от истории философии. Таким образом, цели, стоящие перед общим курсом философии и курсом истории и философии науки, гораздо успешнее могут быть достигнуты при простом увеличении продолжительности курса философии для студентов. В таком случае и задача курса для аспирантов - освещение философии науки - могла бы решаться гораздо успешнее, поскольку подготовленность обучающихся к нему была бы гораздо выше. Для успешного решения задачи выведения науки на более высокий уровень научности, а значит, и оптимизации ее влияния на общество необходимо, чтобы философия преподавалась студенту в вузе в течение нескольких лет.

Третья из предложенных Фихте мер - обеспечение учащимся на период учебы материального достатка - в настоящий момент ничуть не менее актуальна, чем рассмотренные выше. Очевидно, что качество обучения во многом зависит от мотивированности учащегося. Когда его существование не обеспечено с материальной стороны и он вынужден параллельно с учебой зарабатывать себе на жизнь, учащийся не просто имеет меньше времени на учебу, но оказывается в таком положении, что его ценностные ориентации и личностные навыки формируются нравственной 
атмосферой не столько университета, сколько тех сообществ, от включения в которые зависит его материальное существование. Поскольку материальная потребность в этой ситуации более насущна, то знание, преподаватель и ученый как их носитель не получают у учащегося необходимого для успеха обучения авторитета. Кроме того, по той же причине студенты не образуют те неформальные, ориентированные на знание общности, о необходимости которых для успеха обучения пишет Фихте. В такой ситуации бо́льшая часть усилий государства, системы образования и обучающих уходит в песок, и государство, думая сэкономить, теряет гораздо больше. Можно согласиться с тем, что материальная поддержка учащихся должна быть дифференцированной в зависимости от их успехов. Но и в этом случае в своем максимальном виде она должна полностью обеспечивать материальные потребности студента и быть сравнимой с заработком, который он мог бы получать, пренебрегая учебой. Кроме того, этот максимальный уровень обеспечения должен быть гораздо более массовым, чем сейчас, при обеспечении же студентов классических, ориентированных на науку, а не на технику университетов, эта поддержка однозначно должна исходить от государства, а не от частных лиц и компаний, заинтересованных лишь в технических результатах учебы, а не в науке как таковой.

В данной статье мы коснулись только самых общих и, на наш взгляд, наиболее продуктивных моментов концепции университета немецкого классика. Разумеется, они не исчерпывают собой всех необходимых для успешного развития науки и высшего образования мер. Но представляется, что в них содержатся вполне конкретные и адекватные ответы на современные вопросы о путях развития высшей школы и, что еще более важно, их дух, в отличие от многих предлагавшихся решений, отвечает духу университета и образования и способен не удушить их вместе с наукой, но придать им новое дыхание.

\section{Литература}

1. Фихте И. Г. Речи к немецкой нации. СПб.: Наука, 2009. 349 с.

2. Fichte J.G. Deducirter Plan einer zu Berlin zu errichtenden höheren Lehranstalt (1807) // Johann Gottlieb Fichtes sämmtliche Werke / Hrsg. von I. H. Fichte: 8 Bde. Berlin, Veit \& Comp., 1845/1846. Bd. 8. S. 95-204.

3. Фихте И.Г. Несколько лекций о назначении ученого // Фихте И. Г. Соч.: в 2 т. СПб.: Мифрил, 1993. Т.2. С.7-64.

4. Фихте И.Г. О сущности ученого и ее явлениях в области свободы // Фихте И.Г. Наставление к блаженной жизни. М.: Канон+, 1997. С. 169-258.

5. Фихте И.Г. О понятии наукоучения или так называемой философии // Фихте И.Г. Соч.: в 2 т. СПб.: Мифрил, 1993. Т. 1. С.7-64.

6. Фихте И.Г. Основа общего наукоучения // Фихте И.Г. Соч.: в 2 т. СПб.: Мифрил, 1993, Т.1. C. $65-337$.

Для цитирования: Иваненко А. А. И. Г. Фихте об университетском образовании // Вестник СПбГУ. Философия и конфликтология. 2017. Т. 33. Вып. 4. С. 456-464.

https://doi.org/10.21638/11701/spbu17.2017.407

\section{References}

1. Fichte J.G. Rechi k nemetskoi natsii [Adresses to the German Nation]. St. Petersburg, Nauka Publ., 2009. 349 p. (In Russian)

2. Fichte J.G. Deduzierter Plan einer zu Berlin zu errichtenden höheren Lehranstalt (1807). Johann Gottlieb Fichtes sämtliche Werke. Hrsg. von I. H. Fichte. 8 Bde. Berlin, Veit \& Comp., 1845/1846. Bd. 8, pp. 95-204. 
3. Fichte J. G. Neskol'ko lektsii o naznachenii uchenogo [Several lectures on the Vocation of the Scholar]. Fichte J. G. Sochineniia [Works]. In 2 vol. St. Petersburg, Mifril Publ., 1993, vol. 2, pp. 7-64. (In Russian)

4. Fichte J.G. O sushchnosti uchenogo i ee iavleniiakh v oblasti svobody [On the nature of the Scholar and its manifestations in the field of freedom]. Fichte J. G. Nastavlenie k blazhennoi zhizni [Manual to the blessed life]. Moscow, Canon+ Publl., 1997, pp. 169-258. (In Russian)

5. Fichte J. G. O poniatii naukoucheniia ili tak nazyvaemoi filosofii [On the concept of Science of Knowledge or so-called philosophy]. Fichte J. G. Sochineniia [Works]. In 2 vol. St. Petersburg, Mifril Publ., 1993. vol. 1, pp. 65-337. (In Russian)

6. Fichte J.G. Osnova obshchego naukoucheniia [Foundations of the Entire Science of Knowledge]. Fichte J. G. Sochineniia [Works]. In 2 vol. St. Petersburg, Mifril Publ., 1993, vol. 1, pp. 7-64. (In Russian)

For citation: Ivanenko A. A. J. G. Fichte about university education. Vestnik SPbSU. Philosophy and Conflict Studies, 2017, vol. 33, issue 4, pp. 456-464. https://doi.org/10.21638/11701/spbu17.2017.407

Статья поступила в редакцию 2 июня 2017 г. Статья принята в печать 13 июня 2017 г. 